\title{
Exploring Influencing Factors towards Intention and Use of Mobile Internet for Youth Consumers in Bangladesh
}

\author{
Mohammad Majedul Islam \\ Department of Marketing, University of Rajshahi, Bangladesh
}

Copyright $(2017$ by authors, all rights reserved. Authors agree that this article remains permanently open access under the terms of the Creative Commons Attribution License 4.0 International License

\begin{abstract}
This paper investigates the factors played significant role to use mobile internet services. A research framework was developed to testify the statistical relationships and a survey instruments were employed on mobile internet users to collect data from 413 students from five Universities. The UTAUT model of technology acceptance and use has been utilized as theoretical framework to measure the effects of the factors that account for intention and use of the mobile internet. A multiple regression analysis is carried out to determine the attributes that affect the intention and use of mobile internet. The study reveals that performance expectancy, effort expectancy, social influence, perceived risk, and personalization appear significant among the six attributes to influence behavioral intention and behavioral intention and facilitating conditions perform significant factors to influence actual use of mobile internet. The findings may provide feedback and contribute to the improvement of service providers' strategy and marketing program.
\end{abstract}

Keywords Influencing Factors, Behavioral Intention, Use Behavior, Mobile Internet, Youth Consumers, Bangladesh

\section{Introduction}

Mobile internet or wireless Internet enables wireless connectivity to the Internet via radio waves rather than wires on a person's home computer, laptop, smartphone or similar mobile device. Wireless Internet can be accessed directly through providers like Grameen Phone, Teletalk, AT\&T, Verizon, T-Mobile, Banglalion and Qubee. As cell phones with mobile internet capability shift from being a luxury to a necessary commodity, the mobile internet is becoming increasingly adopted by regular consumers. The mobile internet makes internet connection accessible and universal, while adding value to consumers' lives in line with the ever more mobile lifestyles of modern society. The vast deployment in third generation (3G) mobile networks has been taken place in Bangladesh. For getting the return on investments made in network and service infrastructure, new and beneficial services should be industrialized and disseminated which will acknowledge by the consumers.

At present world internet penetration is $42.06 \%$ whereas Bangladesh is having only $17.42 \%$ in 2013 [12]. Year after year rate of internet use is increasing in Bangladesh. World Bank data shows that it was only $0.2 \%$ in 2003 and boost up $406.28 \%$ in 2006 over 2005 and $81.06 \%$ average rate of increase in last five years. For the availability of mobile devices to use internet progressed its rate increase. An estimated $90 \%$ of Bangladesh's Internet users got their access using mobile services in 2010. Internet penetration remains low (0.4\% user penetration coming into 2011) and Internet subscription rates are considerably lower. The total number of Internet Subscribers in Bangladesh has reached $35,790,146$ at the end of 2013 where Mobile Internet has 34,249,731 (95.7\%), ISP and PSTN 1,224,620 (3.4\%), and WiMAX has $315,795(0.9 \%)$ [5]. So, there are some positive impacts of mobile devices to increase the rate of internet uses in Bangladesh. Bangladesh has positioned at 181st among 212 countries in internet users in 2013 [11]. Same report shows, in South Asian perspective average internet penetration is $17.51 \%$ where Maldives has highest as $38.90 \%$ and Bangladesh is in lowest position. A set of requirements needed to gain widespread adoption of mobile services. The technological infrastructure, business strategic and behavioral changes are main requirements towards mobile internet adoption and use [22].

Furthermore, multi-purposes service requires the combination of upgraded network technologies, diverse content, and complementary services. Secondly, acceptance on the demand side requires extensive adoption of technology and service platforms between content developers and service providers. Lastly, consumers discreetly postulate a set of demand-side requirements those should be meet by the services. To comprehend these requirements, context specific behavior of consumers should be collect and analyze properly. This research aims to investigate behavioral, demand-side adoption requirements towards behavioral intention and use of mobile internet so 
that internet service providers (ISPs) can improve their facilities and make people aware for the development of mobile internet in Bangladesh.

In recent studies, most of the existing researches tried to identify different independent variables including perceived risks, personalization, availability along with basic constructs of UTAUT as performance expectancy, effort expectancy, social influence, and facilitating condition those influences in consumers' decision making process to adopt and use mobile internet services becoming challenging research issues in developing country like Bangladesh.

Due to increasing penetration of mobile phones even in rural low income communities, mobile internet could bring formal communication facilitation for economic uses of mobile phones. Therefore, a comprehensive model for mobile internet consumers' intention and use behavior attracts extensive research interest.

\section{Literature Review}

Regular internet use by university students is evident in all age groups with fairly consistent usage across groups. Additionally, little difference was found among the various age groups regarding their predictions for Internet use in the future [24]. The mobile internet has not yet emerged on a large scale in different countries. On the contrary operators have slightly increased their power, potentially because handset bundling with mobile subscriptions is now allowed [27]. Irrespective of age, institutions, income level, etc.; mobile internet use of university students are very less in Bangladesh [13]. In addition, students' grade level also played an important role in their Internet attitudes; graduate students tended to possess more positive Internet attitudes. More importantly, students' Internet attitudes were highly correlated with their Internet self-efficacy [29]. There are some nations those are more progressing in terms of accessibility, utilization, and usage of technology as provided availability of technology [26][1]. Again, there are significant differences in the users' perceptions of mobile internet usage (MIU) during its different innovation diffusion stages where perceived enjoyment is the most important predictor of MIU [18]. The service quality variables (i.e., information quality, connection quality, ease of use, and service charge) are major determinants to overall satisfaction which affects a consumer's intention to continue using the service [15].

Attitude toward M-internet is the most significant factor in predicting the behavioral intention to use M-internet. Also identifies the positive role of the perceived playfulness and the negative role of perceived price level in developing the attitude as well as the intention. The positive causal relationships of "perceived contents quality - perceived usefulness", "perceived system quality- perceived usefulness" and "internet experience-perceived ease of use" were also witnessed [6]. Again, Social influence and self-efficacy are significantly affecting to perceived usefulness and perceived ease of use, respectively. Then both perceived usefulness and perceived ease of use explain significantly to the variations in the attitude for using the mobile Internet which again influences the actual usage [17]. There are strong causal relationships between the social influences, personal innovativeness and the perceptual beliefs - usefulness and ease of use, which in turn impact adoption intentions toward wireless internet [20]. Furthermore, factors of flow including perceived enjoyment and attention focus have strong effects on user satisfaction, which further affects continuance usage.

In addition, performance expectancy, social influence and facilitating conditions also affect continuance usage [30]. Consumers' attitude towards perceived usefulness and perceived ease of use describe significantly to the variations in the customer's intention to use and actual usage of the mobile Internet. Additionally, several insights into the cultural factors also affect mobile phone Internet usage in different markets [10]. Perceived personalization or self-service option also has significant impacts on consumers' trust to influence the intention to adopt technology usage [3] [16] [7]. The perceived risk indirectly impacts consumers' intention to use technology having strong influence to continuous use [19]. It has a negative impact on behavioral intention to use technology through reducing trust [4] [8].

The behavioral intention and use behavior in the adoption of mobile Internet is explained by the variables habit, facilitating conditions, hedonic motivation, performance expectancy, price value and social influence [23]. Internet adoption at the user level can be viewed as a three-layered pyramid. It consists of seven moderating factors (age, gender, experience, voluntary use, friends' influence, Internet service providers and regulators), four indirect determinants (performance expectancy, effort expectancy, social influence and facilitating conditions) and three direct determinants (education, behavioral intention and income) [25]. Social influence through interpersonal and external influences impacted beliefs about the usefulness and likely enjoyment of using mobile Internet. Perceived behavioral control and perceived enjoyment also had direct impacts on adoption intention.

Individual differences or personal expectation is regarded as the most relevant variables for technological interaction [31] [33] [35] [36] [40] [42]. It seems that personalization has been generally expected to be related to online usage and assess user's acceptance motivations and preferences [34] [41]. So, personalization impact on behavioral intention of online transaction [37].

Interestingly, our findings indicate that early adopters value ease of use, confidently relying on their own m-payment knowledge, whereas they respond very positively most notably reachability and convenience of usage [37]. Reachability of the mobile devices makes it possible for people to be contacted anytime and anywhere, and provides users with the choice to limit their reachability to particular people or times [32] [38] [39]. Reachability will have a positive effect on the perceived ease of use of 
m-payment. So, availability has a positive effect on the behavioral intention to online transaction [37].

However, perceived usefulness, interpersonal influence and external influence did not have a direct influence on adoption intention [21]. Finally, performance expectancy, effort expectancy, social influence, perceived value and palm-sized computer self-efficacy were significant determinants of behavioral intention to use m-Internet [28].

\section{Proposed Model and Research Hypotheses}

Although, there are growing interests in understanding of the use of mobile Internet in different applications but its actual use has not spreader enough. By the way, understanding of factors behind diffusion and acceptance of the mobile Internet is one important research issue to be explored.

The literatures review relevant either on technology acceptance model (TAM) or unified theory of acceptance and use of technology (UTAUT) and field study, this study proposed a research model in an attempt to explain influences in adoption and use of mobile Internet by the university students in Bangladesh.

Considering the theoretical framework of UTAUT, different literatures and field study it would be logically hypothesized that positive perception of mobile internet will lead to early use and negative perception on Internet will lead to late use of the mobile internet service by the youth consumers in Bangladesh. Understanding the above proposed model the hypotheses might be:

H1: The behavioral intention to use will have positively direct impact on the actual use of mobile internet in Bangladesh

$\mathrm{H}$ 2: The facilitating conditions will have positively direct impact on the actual use of mobile internet in Bangladesh

H3: The performance expectancy will have positively direct impact on the behavioral intention to use mobile internet in Bangladesh

H4: The effort expectancy will have positively direct impact on the behavioral intention to use mobile internet in Bangladesh

H5: The social influence will have positively direct impact on the behavioral intention to use mobile internet in Bangladesh

H6: The perceived risks will have negatively reverse impact on the behavioral intention to use mobile internet in Bangladesh

H7: The personalization will have positively direct impact on the behavioral intention to use mobile internet in Bangladesh H8: The availability of mobile internet service will have positively direct impact on the behavioral intention to use mobile internet in Bangladesh

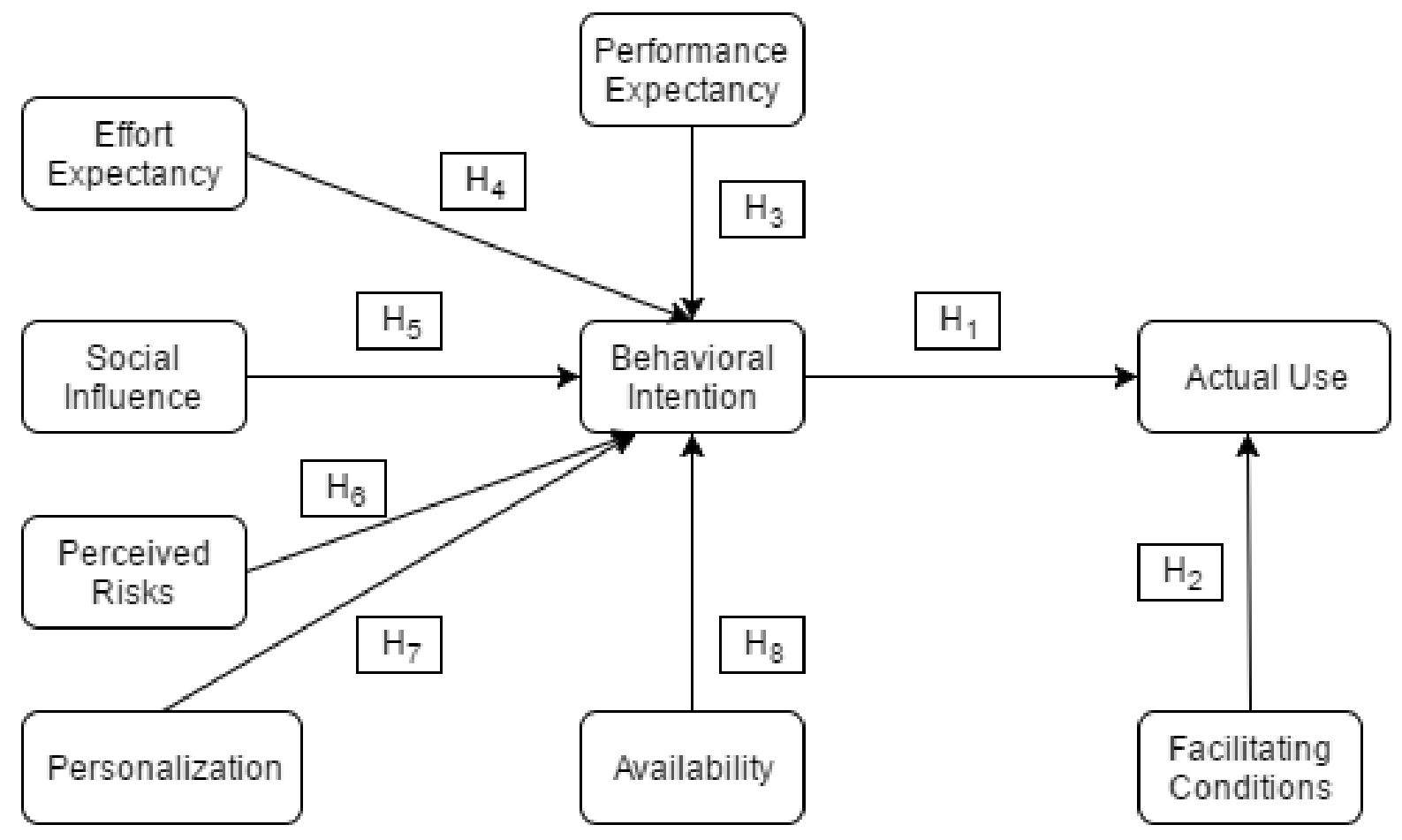

Figure 1. Proposed research model 


\subsection{Questionnaire}

The questions in the questionnaire were based on review of literatures and the field study of University students of Bangladesh. The specific characteristics represented different services and facilities provided by the mobile network operators (MNOs) and expected by the youth segments of mobile internet consumers in Bangladesh. The questionnaire was translated into Bengali language to make clear and simple to understand by every respondent. The items in the questionnaire were constructed based on the consumers' adoption intention and use of mobile internet.

The constructs/factors have been adopted from existing literatures and field survey. It was consisted of 29 questionnaire items on eight factors including "actual use," "perceived risk," "personalization," "social influence", "effort expectancy", "performance expectancy", "social influence", "availability", and "perceived risks." The items of these factors were presented in a seven-point Likert scale, ranging from "excellent," "Very Good," "Good," "Fair," "Not So Good," "Poor," and "Don't Know". The use of such scale expressed differentiation for students' variation of agreement in greater detail.

\subsection{Data Collection}

Data were collected from students survey, where students gatherings in different places of university campuses. Students were selected randomly from different classes and faculties where $61.2 \%$ students were from two public universities and $38.8 \%$ from three private universities. Though the study was held in Rajshahi region, respondents represented from eight divisions out of nine divisions in Bangladesh. The respondents were using mobile internet either through Wi-Fi $(12.8 \%)$, mobile data $(57.4 \%)$, or modem $(29.8 \%)$.

The researcher collected information through delivering questionnaire and asking questions from different group of students.

\subsection{Statistical Analysis}

As far as scale-based variables were concerned, principal factor analysis was performed. In this study, the correlation matrix was used to obtain Eigen values. To facilitate the interpretation of factor loading, VARIMAX rotation was performed. In addition, Pearson correlation analyses were also conducted to examine the relationships among the constructs. SPSS software version 20 was used for analyzing the data.

\section{Results and Discussion}

\subsection{Reliability Coefficient}

The reliability coefficient has been tested by using Cronbach's alpha $(\alpha)$ analysis. Cronbach alpha is a commonly used method to measure the reliability for a set of two or more constructs where higher values indicate greater reliability of the indicators [9]. Cronbach's alpha tested here those found the total scale of reliability for this research varies from 0.519 to 0.726 , which indicates overall good reliability factors (Table 1 ).

\subsection{Factor Analysis}

The results obtained from 413 respondents had been thoroughly analyzed. The Principal Component Analysis (PCA) has been accepted in SPSS to find the primary factors related with 29 items. The factors' validity has been tested on the basis of Bartlett's Test of Sphericity and the Kaiser-Mayer-Olkin (KMO). It has measured the adequacy of sampling on the basis of strength of relationship of different factors. The result of the Bartlett's Test of Sphericity and KMO shows the significance (0.759) and appropriateness for the factor analysis (Table 2).

The numbers of factors those are difficult to retain initially runs-based on Eigenvalues showed 9 factors explained $59.22 \%$ of total variance (Table 3 ). The minimum loading required to contain an item in its respective constructs, loading 0.50 or greater are very significant (Hair, Anderson, Tatham, \& Black, 1992). Here, the overall criteria for selected items were 0.50 loading points or greater.

The factor analysis revealed nine factors affiliated from 29 items (Table 1). In general, the factor is the normal affinity of an item for a group. The higher factor loading indicates the stronger relationship of an item to a particular construct. The findings of this study direct that the nine factors: actual use $(\mathrm{AU})$, perceived risk (PR), availability (AV), performance expectancy (PE), personalization (PS), facilitating conditions (FC), behavioral intention (BI), social influence (SI), and effort expectancy (EE) were evenly loaded to the different constructs. Every item that loaded into nine different factors has been supported for significantly related to the youth consumers' anticipation.

\subsection{Multiple Regression Analysis}

The performance of regression analysis should be justified with the normality of distribution and no presence of multi-collinearity among the indigenous variables. The normality has been checked through histogram (Figure 2 and Figure 3) while the multi-collinearity has been examined through tolerance level and VIF value of regression statistics. 
Table 1. Reliability analysis and Factor loading matrices

\begin{tabular}{|c|c|c|c|c|c|c|c|c|c|c|c|c|}
\hline Item & $\mathrm{AU}$ & PR & $\mathrm{AV}$ & PE & PS & $\mathrm{FC}$ & BI & SI & $\mathrm{EE}$ & Alpha & Mean & $\begin{array}{c}\text { Std. } \\
\text { Deviation }\end{array}$ \\
\hline GAS & 0.74 & & & & & & & & & \multirow{5}{*}{0.726} & 5.04 & 1.61 \\
\hline SMT & 0.74 & & & & & & & & & & 4.31 & 1.64 \\
\hline UID & 0.69 & & & & & & & & & & 5.24 & 1.58 \\
\hline WIU & 0.63 & & & & & & & & & & 1.72 & 1.03 \\
\hline IAU & 0.53 & & & & & & & & & & 4.86 & 1.64 \\
\hline FUS & & 0.77 & & & & & & & & \multirow{4}{*}{0.643} & 4.56 & 1.70 \\
\hline WPI & & 0.71 & & & & & & & & & 4.92 & 1.70 \\
\hline WOT & & 0.67 & & & & & & & & & 4.82 & 1.66 \\
\hline HNT & & 0.57 & & & & & & & & & 3.49 & 1.78 \\
\hline AWA & & & 0.74 & & & & & & & \multirow{4}{*}{0.631} & 4.21 & 1.68 \\
\hline NDU & & & 0.69 & & & & & & & & 3.46 & 1.59 \\
\hline ATA & & & 0.65 & & & & & & & & 4.63 & 1.64 \\
\hline SIF & & & 0.51 & & & & & & & & 3.52 & 1.51 \\
\hline ANW & & & & 0.75 & & & & & & \multirow{3}{*}{0.594} & 5.28 & 1.48 \\
\hline SAM & & & & 0.71 & & & & & & & 5.74 & 1.44 \\
\hline ANT & & & & 0.57 & & & & & & & 6.08 & 1.06 \\
\hline SPI & & & & & 0.74 & & & & & \multirow{3}{*}{0.627} & 4.65 & 1.75 \\
\hline PPI & & & & & 0.73 & & & & & & 5.17 & 1.53 \\
\hline PP & & & & & 0.56 & & & & & & 5.17 & 1.48 \\
\hline ICS & & & & & & 0.78 & & & & \multirow{3}{*}{0.620} & 4.04 & 1.63 \\
\hline $\mathrm{CSA}$ & & & & & & 0.70 & & & & & 4.77 & 1.62 \\
\hline UPI & & & & & & 0.62 & & & & & 4.11 & 1.64 \\
\hline FNFT & & & & & & & 0.81 & & & \multirow{2}{*}{0.746} & 5.43 & 1.39 \\
\hline SUPT & & & & & & & 0.80 & & & & 5.61 & 1.39 \\
\hline FNU & & & & & & & & 0.78 & & \multirow{3}{*}{0.634} & 5.39 & 1.52 \\
\hline WSU & & & & & & & & 0.75 & & & 5.53 & 1.47 \\
\hline WEF & & & & & & & & 0.61 & & & 5.15 & 1.55 \\
\hline EAC & & & & & & & & & 0.71 & \multirow{2}{*}{0.519} & 5.69 & 1.30 \\
\hline FAP & & & & & & & & & 0.52 & & 5.24 & 1.36 \\
\hline
\end{tabular}

Table 2. KMO and Bartlett's test

\begin{tabular}{|l|c|c|}
\hline \multicolumn{2}{|c|}{ Kaiser-Meyer-Olkin Measure of Sampling Adequacy. } & 0.759 \\
\hline \multirow{3}{*}{$\begin{array}{c}\text { Bartlett's Test } \\
\text { of Sphericity }\end{array}$} & Approx. Chi-Square & 2711.112 \\
\cline { 2 - 3 } & $\mathrm{df}$ & 406 \\
\cline { 2 - 3 } & Sig. & 0 \\
\hline
\end{tabular}

Table 3. Total variance explained

\begin{tabular}{|c|c|c|c|c|c|c|}
\hline \multirow{2}{*}{ Factors } & \multicolumn{3}{|c|}{ Initial Eigenvalues } & \multicolumn{3}{c|}{ Extraction Sums of Squared Loadings } \\
\cline { 2 - 7 } & Total & \% of Variance & Cumulative \% & Total & \% of Variance & Cumulative \% \\
\hline 1 & 4.856 & 16.745 & 16.745 & 4.856 & 16.745 & 16.745 \\
\hline 2 & 2.248 & 7.753 & 24.498 & 2.248 & 7.753 & 24.498 \\
\hline 3 & 1.962 & 6.767 & 31.265 & 1.962 & 6.767 & 31.265 \\
\hline 4 & 1.732 & 5.971 & 37.235 & 1.732 & 5.971 & 37.235 \\
\hline 5 & 1.534 & 5.29 & 42.525 & 1.534 & 5.290 & 42.525 \\
\hline 6 & 1.364 & 4.703 & 47.229 & 1.364 & 4.703 & 47.229 \\
\hline 7 & 1.273 & 4.390 & 51.619 & 1.273 & 4.390 & 51.619 \\
\hline 8 & 1.194 & 4.118 & 55.737 & 1.194 & 4.118 & 55.737 \\
\hline 9 & 1.010 & 3.483 & 59.220 & 1.010 & 3.483 & 59.220 \\
\hline
\end{tabular}




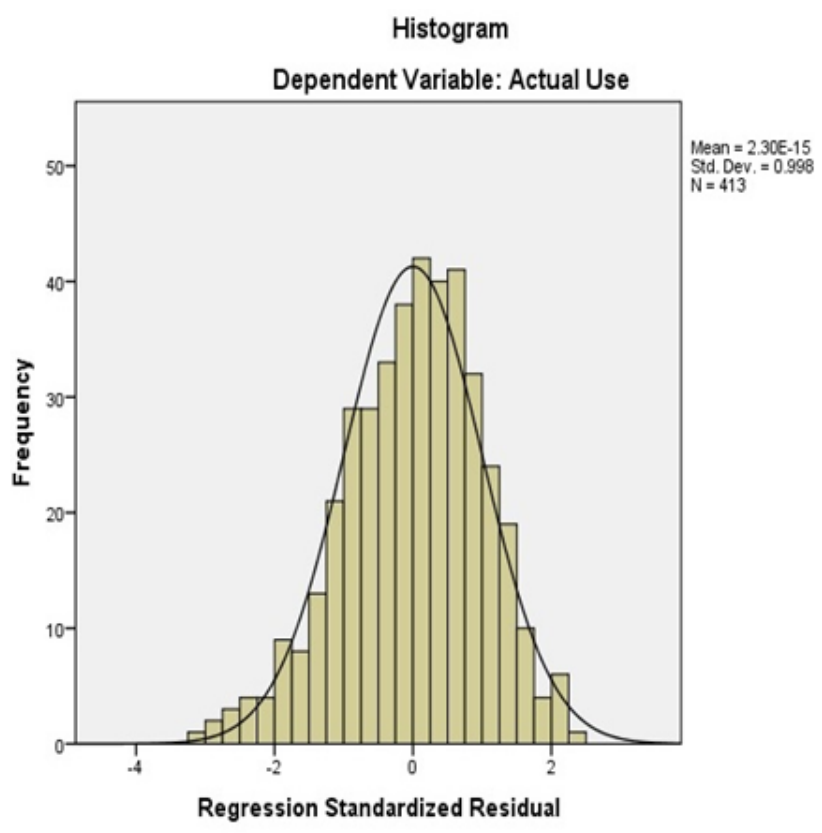

Figure 2. Normality of distribution of Model 1

The model 2 run results indicate the 6 characteristics (performance expectancy, effort expectancy, social influence, personalization, availability, and perceived risks) considered in the model account for $53 \%$ mobile internet adoption intention by the youth consumers in Bangladesh.

The study showed that seven hypotheses were supported out of eight hypotheses significant at $\mathrm{p}<0.05$. The behavioral intention to use has positively direct impact on the actual use of mobile internet in Bangladesh. Therefore, $\mathrm{H} 1$ has not rejected at the 0.5 level of significance. Regarding $\mathrm{H} 2$, the facilitating conditions have positively direct impact on the actual use of mobile internet in Bangladesh.
Therefore, this hypothesis also has accepted at the 0.5 level of significance. Furthermore, hypotheses H3, H4, H5, $\mathrm{H} 6$, and $\mathrm{H} 7$ have been supported at the 0.5 level of significance. So, performance expectancy, effort expectancy, social influence, and personalization have positively direct impact and perceived risk has negatively reverse impact on behavioral intention to use of mobile internet in Bangladesh.

Finally, H8 has not been supported at the 0.5 level of significance. It shows 0.826 as $\mathrm{p}$ value which is more than 0.5 and it has failed to prove that the availability of mobile internet service has direct impact on the behavioral intention to use mobile internet in Bangladesh.

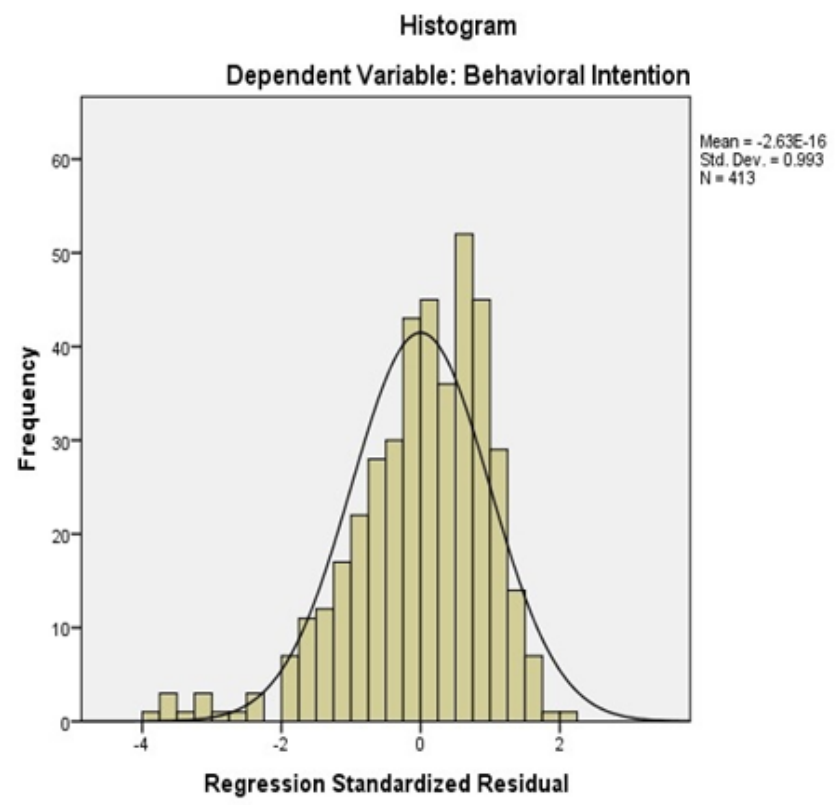

Figure 3. Normality of distribution of Model 2

Table 4. Regression Statistics Model 1

\begin{tabular}{|c|c|c|c|c|c|c|}
\hline Model 1 & & Coefficients & $\mathrm{t}$ & Sig. & \multicolumn{2}{|c|}{ Collinearity Statistics } \\
\hline \multirow{8}{*}{$\begin{array}{l}\text { Dependent Variable: } \\
\text { Actual Use (AU) }\end{array}$} & & beta & & & Tolerance & VIF \\
\hline & (Constant) & & 11.766 & 0.000 & & \\
\hline & BI & 0.137 & 02.743 & 0.006 & 0.926 & 1.08 \\
\hline & $\mathrm{FC}$ & 0.145 & 02.909 & 0.004 & 0.926 & 1.08 \\
\hline & $\mathrm{R}^{2}$ & 0.510 & & & & \\
\hline & Adjusted $\mathrm{R}^{2}$ & 0.460 & & & & \\
\hline & F value & 10.972 & & & & \\
\hline & Durbin-Watson & 1.732 & & & & \\
\hline
\end{tabular}


Table 5. Regression Statistics Model 2

\begin{tabular}{|c|c|c|c|c|c|c|}
\hline Model 2 & & Coefficients & $\mathrm{t}$ & Sig. & Colli & \\
\hline \multirow{12}{*}{$\begin{array}{l}\text { Dependent Variable: } \\
\text { Behavioral Intention } \\
\text { (BI) }\end{array}$} & & beta & & & Tolerance & VIF \\
\hline & (Constant) & & 4.938 & 0.000 & & \\
\hline & $\mathrm{PE}$ & 0.111 & 2.140 & 0.033 & 0.799 & 1.252 \\
\hline & $\mathrm{EE}$ & 0.098 & 1.836 & 0.067 & 0.746 & 1.341 \\
\hline & SI & 0.072 & 1.438 & 0.151 & 0.855 & 1.170 \\
\hline & PS & 0.214 & 4.160 & 0.000 & 0.811 & 1.233 \\
\hline & AV & 0.011 & 0.220 & 0.826 & 0.814 & 1.228 \\
\hline & PR & -0.058 & 1.225 & 0.221 & 0.950 & 1.052 \\
\hline & $\mathrm{R}^{2}$ & 0.53 & & & & \\
\hline & Adjusted $\mathrm{R}^{2}$ & 0.48 & & & & \\
\hline & F value & 10.339 & & & & \\
\hline & Durbin-Watson & 1.591 & & & & \\
\hline
\end{tabular}

\section{Conclusions and Implications}

This study was attempted to examine and understand the youth consumers' behavioral intention and use attitude towards mobile internet in selecting mobile network operators and Wi-Fi service providers in Bangladesh. The mobile internet service providers business faced intense competition in attracting and acquiring the existing and potential consumers through huge involvement in market and trade promotion.

Presently, they are highly competing for providing value added services through mobile internet along with network quality, network extension and upgradation. According to this study, personalization is the highest significant factors following performance expectancy, effort expectancy, social influence, and perceived risks to influence behavioral intention to use mobile internet to the youth consumers in Bangladesh. Again, behavioral intention to use and facilitating conditions both are almost equally important to drive actual use of mobile internet of youth consumers in Bangladesh.

The primary theoretical contribution of this study is the identification of factors that can be used to enlighten and foretell youth consumers' intention and use of mobile internet, particularly within the Bangladesh context. This research also creates a research interest on mobile internet for the business researchers. Secondly, personalization has been found as strong factors along with existing factors of UTAUT model relevant to mobile internet that were absent in previous researches. Again, it has created eagerness to future study for investigation of relationship between mobile internet and mobile commerce. Finally, the findings of the study can help mobile internet service providers in their operation and strategic plan of marketing of value added services through mobile internet.

\section{Limitation and Future Research}

The main limitation of this study was the lack of sample representation. The university students were used as the sample which is limited to generalize the results drawn from their responses though the current users of the mobile Internet in Bangladesh are mostly younger generations. In spite of this problem, the present study has made good contribution to initiate interest in research to develop and apply theory and while there were few studies directed to addressing the issue of behavioral intention and use of mobile internet. In case of future research, it can be focus on a comparative study with the measures of age, gender, experience, voluntary use of mobile internet users with more representative respondents.

\section{REFERENCES}

[1] Adedeji, T. (2011). Availability and Use of ICT in South-Western Nigeria. International Multidisciplinary Journal, 5(5), 315-331.

[2] Azam, M. (2007). Internet Adoption and Usage in Bangladesh. Japanese Journal of Administrative Science, 20(1), 43-54.

[3] Benbasat, I., \& Komlak, S. Y. (2006). The Effects of Personalization and Familiarity on Trust and Adoption of Recommendation Agents. MIS Quarterly, 30(4), 941-960. Retrieved from http://www.jstor.org/stable/25148760

[4] Bisht, A. (2012). The impact of trust and perceived risk on internet banking adoption in India. International Journal of Bank Marketing, 30(4), 303-322. Retrieved from http://dx.doi.org/10.1108/02652321211236923

[5] Bmoninfo. (2012). Total Internet Subscribers at the end of February 2012. Dhaka: Bangladesh Mobile Operators News. Retrieved from

http://bmoninfo.wordpress.com/2012/04/05/total-internet-sub scribers-at-the-end-of-february-2012/ 
[6] Cheong, J., \& Park, M. (2005). Mobile internet acceptance in Korea. Internet Research, 15(2), 125 - 140.

[7] Dhabolkar, P. A. (1996). Consumer evaluations of new technology-based self-service options: An investigation of alternative models of service quality. International Journal of Research in Marketing, 13, 29-51.

[8] Featherman, M. S., \& Pavlou, P. A. (2003). Predicting e-services adoption: a perceived risk facets perspective. International Journal Human-Computer Studies, 59, 451-474. doi:10.1016/S1071-5819(03)00111-3

[9] Hair, J., Anderson, R., Tatham, R., \& Black, W. (1992). Multivariate Data Analysis (3rd ed.). New York: Macmillan.

[10] Hamed, Z., Ramin, Qadim, \& Vatanparast. (2009). A CROSS-CULTURAL STUDY ON MOBILE INTERNET USAGE. International Journal of Mobile Marketing, 4(2), 14-27.

[11] Internet Usage in Asia. (2015, December 12). Retrieved from Internet World Stats: http://www.internetworldstats.com/stats3.htm

[12] Internet users. (2016, March 22). Retrieved from The World Bank Data: http://data.worldbank.org/indicator/IT.NET.USE R.P2

[13] Islam, M. M., \& Hossain, M. E. (2013). University Students Attitudes towards Mobile Internet Uses: A Study on Four Universities in Northern Region of Bangladesh. 1st International Conference on Entrepreneurship, SMEs Development and Management (pp. 274-281). Rajshahi: Faculty of Business Studies, University of Rajshahi and UKM-CESMED.

[14] Kendall, J., Tung, L., Chua, K., Ng, C., \& Tan, S. (2001). Receptivity of Singapore's SMEs to electronic commerce adoption. Journal of Strategic Information Systems, 10, 223-242.

[15] Kim, D., \& Steinfield, C. (2004). Consumers Mobile Internet Service Satisfaction and their Continuance Intentions. Americas Conference on Information Systems (AMCIS). AIS Electronic Library (AISeL).

[16] Langeard, E., Betson, J., Lovelock, C., \& Eiglier, P. (1981). Marketing of services: New insights from consumers and managers. Cambridge, MA: Marketing Science Institute.

[17] Lee, W. J., Kimb, T. U., \& Chung, J. (2002). USER ACCEPTANCE OF THE MOBILE INTERNET. Athens: M-Business: Citeseer.

[18] Liu, Y., \& Li, H. (2010). Mobile internet diffusion in China: an empirical study. Industrial Management \& Data Systems, $110(3), 309-324$.

[19] Lu, H., Hsu, C., \& Hsu, H. (2005). An empirical study of the effect of perceived risk upon intention to use online applications. Information Management \& Computer Security, 13(2), 106-120. doi:10.1108/09685220510589299

[20] Lu, J., Yao, E. J., \& Yu, C. (2005). Personal innovativeness, social influences and adoption of wireless Internet services via mobile technology. Journal of Strategic Information Systems, 14, 245-268.

[21] Mills, A., Tennant, V., \& Chevers, D. (2011). Understanding Mobile Internet Diffusion: The Case of Jamaica. GlobDev
2011, (p. Paper 6). Retrieved from

http://aisel.aisnet.org/globdev2011/6

[22] Pedersen, P. (2005). Adoption of Mobile Internet Services: An Exploratory Study of Mobile Commerce Early Adopters. JOURNAL OF ORGANIZATIONAL COMPUTING AND ELECTRONIC COMMERCE, 15(2), 203-222.

[23] Ramírez-Correa, P., \& Rondán-Cataluña, F. (2014). An empirical analysis of mobile Internet acceptance in Chile. Information Research, 19(3). Retrieved from http://InformationR.net/ir/19-3/paper635.html

[24] Timothy, T., Perry, Leslie, A., \& Karen, H. (1998). Internet use by university students: an interdisciplinary study on three campuses. Internet Research, 8(2), 136 - 141.

[25] Touraya, A., Salminena, A., \& Mursub, A. (2015). Internet Adoption at the User Level: Empirical Evidence from The Gambia. Information Technology for Development, 21(2), 281-296. doi:10.1080/02681102.2013.874319

[26] US Department of Education. (2001). E-Learning-putting a world class education at the fingertips of all children. New York, USA: Office of Educational Technology, National Educational Technology Development Plan.

[27] Verkasalo, H. (2009). Analysis of mobile internet usage among early-adopters. Emerald Group Publishing Limited, 11(4), 68-82. doi:10.1108/14636690910970982

[28] Wang, H., Chan, T., Huang, Y., Wang, N., \& Chang, Y. (2010). Research Hypotheses for Gender Activities in Mobile Internet. IWCMC'10. Caen, France.

[29] Wu, Y., \& Tsai, C. (2006). University Students' Internet Attitudes and Internet Self-Efficacy: A Study at Three Universities in Taiwan. CYBERPSYCHOLOGY \& BEHAVIOR, 9, 441-450.

[30] Zhou, T. (2011). Understanding mobile Internet continuance usage from the perspectives of UTAUT and flow. Information Development, 27(3), 207-218.

[31] Agarwal, R., \& Prasad, J. (1999). Are individual differences Germane to the acceptance of new information technologies? Decision Sciences, 30(2), 361-391.

[32] Au, Y., \& Kauffman, R. (2008). The economics of mobile payments: Understanding stakeholder issues for an emerging financial technology application. Electronic Commerce Research and Applications, 7, 141-164.

[33] Chen, C., Czerwinski, M., \& Macredie, R. (2000). Individual differences in virtual environments - Introduction and overview. Journal of the American Society for Information Science, 51(6), 499-507.

[34] Coursaris, C., \& Hassanein, K. (2002). Understanding M-commerce a consumer centric model. Quarterly Journal of Electronic Commerce, 3(3), 247-271.

[35] Dillon, A., \& Watson, C. (1996). User analysis in HCI-the historical lessons from individual difference research. International Journal of Human-Computer Studies, 45(6), 619-637.

[36] Karahanna, E., Ahuja, M., Srite, M., \& Galvin, J. (2002). Individual differences and relative advantage: The case of GSS. Decision Support Systems, 32(4), 327-341. 
[37] Kim, C., Mirusmonov, M., \& Lee, I. (2010). An empirical examination of factors influencing the intention to use mobile payment. Computers in Human Behavior, 26(3), 310-322.

[38] Ng-Kruelle, G., Swatman, P., Rebme, D., \& Hamp, J. (2002). The price of convenience. Privacy and mobile commerce. Quarterly Journal of Electronic Commerce, 3(3), 273-285.

[39] Ondrus, J., Lyytinen, K., \& Pigneur, Y. (2009). Why mobile payments fail? Towards a dynamic and multi-perspective explanation. 42nd Hawaii international conference on system sciences (HICSS'09) (pp. 1-10). Hawaii: IEEE Computer Society.
[40] Sun, H., \& Zhang, P. (2006). The role of moderating factors in user technology acceptance. International Journal of HumanComputer Studies, 64(4), 53-78.

[41] Zmijewska, A., Lawrence, E., \& Steele, R. (2004). Towards understanding of factors influencing user acceptance of mobile payment systems. IADIS International Conference. Madrid, Spain.

[42] Zmud, R. V. (1979). Individual differences and MIS success: A review of the empirical literature. Management Science, 25(10), 966-979. 